Article

\title{
Socio-economic Factors Affecting Fertilization Sustainability in Bangladesh: Effects of Traditional Way of Fertilization and Rental Land Farming
}

\author{
K. M. Atikur Rahman ${ }^{*}$, and Dunfu Zhang ${ }^{2}$ \\ 1 School of Sociology and Political Science, Shanghai University, China; 99, Shangda Road, Shanghai, China-200444; \\ e-mail: atik73@i.shu.edu.cn \\ 2 School of Sociology and Political Science, Shanghai University, 99, Shangda Road, Shanghai, China-200444; \\ e-mail: paulchang@staff.shu.edu.cn \\ Correspondence: E-mail: atik73@i.shu.edu.cn; Tel.: +86 18217794872
}

\begin{abstract}
The study focuses on how socio-economic and demographic indicators affect fertilization sustainability (excessive amount of fertilization). Principally we aim to examine the significance magnitude of the effects of three socio-demographic variables such as traditional way of fertilization, rental land farming, and farmers' younger age on over-fertilization in Bangladesh and other developing countries. In 1960s, Bangladesh state authority launched a campaign 'Grow more Food' to feed huge numbers of population and thus the farmers are provided chemical fertilizers and pesticides at a subsidized low price. Farmers began to use huge amount of fertilizers for gaining high yields and continued it to present causing environmental woes a lot. We interview (face-to-face, focus group discussion, and phone interview) 210 Bangladesh farmers in 2016 by semi-structured questionnaire. Data has been analyzed using General Linear Model (GLM) in Univariate Analysis of Variance. The study found the effect of traditional way of fertilization on excessive amount of fertilization is strongly significant at $1 \%$ level. Apart from, rental land farming and farmers' younger age have a significant influence on over- fertilization; though their significance level ( $5 \%$ and $10 \%$ respectively) is quasi-strong. Policy makers can be able to formulate fertilizer policy on the basis of these findings.
\end{abstract}

Keywords: excessive fertilization; agro environment; rental land; traditional way; younger farmers; environmental consciousness

\section{Introduction}

The proportion of the world's people that is hungry has dramatically decreased due to the marked growth in food production in the half past century $[1,2]$. This has significantly decreased the proportion of the malnourished people even as the earth's human population doubled to 9 billion [1]. However the challenges facing the agricultural food production are greater than ever before [3-6]. Because efficiency of resource use and environmental degradation are undergoing and increased global food production must be achieved while improving efficiency of those phenomena [3-6]. The doubling of agricultural food production worldwide up to 1990s can be partly attributed to a 6.9-fold increase in $\mathrm{N}$ fertilization, a 3.5-fold increase in $\mathrm{P}$ fertilization $[3,7]$. It is also worth noting that more than half of the increased crop production in China was based on a rapid increase in the consumption of fertilizers $[8,4]$.

Farmers are some other developing countries apply fertilizers excessively and discriminately. Bangladesh, India, Africa, and Latin America farmer groups belong to such type of unsustainable fertilization causing environmental woes. But the most of the developed countries presently consume chemical fertilizers in a rational amount in consideration of agro ecological aspects. Global atmospheric $\mathrm{N}_{2} \mathrm{O}$ concentrations have increased from the pre-industrial level of $270 \mathrm{ppb}$ to $319 \mathrm{ppb}$ in 2005, with agricultural production [9]. In addition, Food and Agriculture Organization (FAO) predicted that by 2030 global $\mathrm{N}_{2} \mathrm{O}$ emissions from fertilizer application will increase by $35 \%$ to $60 \%$ [10]. It is viewed that fertilizer consumption is a primary source of $\mathrm{N}_{2} \mathrm{O}$, along with industry, mining, and transportation activities. $\mathrm{N}_{2} \mathrm{O}$ is one type of toxic gas that causes drastic ecological risks. In this regards, Bangladesh along with other developing and Least Developed Countries (LDC) contribute huge amount of Green House Gasses (GHG) consuming massive amount of fertilizers and pesticides. Bangladesh uses of inorganic fertilizers worth about $198 \mathrm{KGs}$ per ha $[11,12]$. Massive fertilization deteriorates soil structure and fertilityparticularly potassium and sodium containing fertilizers causes fatal risks in land soils- $\mathrm{p}^{\mathrm{H}}$ value deterioration, increase of acidity in soil and water are persisting a common features in Bangladesh agro ecosystem. Continuous use of acid forming nitrogen fertilizers causes a decrease in $\mathrm{p}^{\mathrm{H}}$, liming, if not carried to prevent the declining efficiency of field crops [13]. 
The link between agriculture and nitrate pollution is well established with impacts of drinking water, and the eutrophication of fresh water and marine ecosystem $[13,14]$. Thus, it is observed that sodium, potassium, nitrogen mixed fertilizers heavily harms soil, water, and air increasing acid, water eutrophication, harmful algal, and decreasing $\mathrm{p}^{\mathrm{H}}$ value. In early 1950s, Bangladesh farmers applied merely organic manures to their croplands [14]. At those periods, agricultural productivity was a little bit less than that of present era; but sustainability in agro environment balanced human lives. In 1965, government launched 'Grow more Food' campaign providing chemical fertilizers and pesticides at a subsidized low price [15]. Farmer groups viewed that those chemical substances worked like magic in cropping culture; continued to use those excessively. As farmers have no educational attainment, training, and agricultural knowledge, they, being influenced by habits, customs, and traditional fertilization way, used fertilizers in mass amounts without consideration of agro environment. Apart from, farmers have to cultivate rental lands having no own land or owning a very small amount of cropland. They rented -in the lands for one year at a high price from elite farmers migrated to different cities. They apply over amount of chemical fertilizers aspiring to gain high yields so that they can reduce their poverty in a short period from the rental lands. Moreover, traditional way of fertilization has been a regular and pronged culture due to non-mechanized agriculture triggering over-fertilization.

Agrochemical use rises sharply in early 1980s and going to be continued till present times in Bangladesh [16]. Bruce [17] reported that fertilizer consumption per hectare in Bangladesh is considerably lower than in many developed countries; but it is higher the average level in many of developing countries. Presently Bangladesh farmers use N, P, and K fertilizers more than other categories because of availability and inexpensiveness [16].

We described the problems of the study to trace out the research questions scientifically. Many of the previous researchers studied on the problems; but some socio-economic causal factors have not yet been studied such as what is the role of rental land farming and traditional way of fertilization (non-mechanized) on over fertilization. We investigate whether rental land farming and traditional way of fertilization (non-mechanized) influences excessive amount of fertilization. The study design includes: literature review, theoretical background, methods and materials, results, discussions and conclusions.

\section{1. $\quad$ Literature Review and Research Questions Development}

We review previous studies to find out the research gaps and rationale of present study. A good number of research works have been conducted on the socio-economic cause factors of massive inorganic fertilization. We review the previous studies critically to identify whether rental land farming and traditional way of fertilization (non-mechanized fertilization) influences excessive amount of fertilization. To find out the gaps and scope of present study we examine prior works categorized into four parts such as: 1. Farmers' knowledge background; 2. Farming Capitals; 3. Fertilizer governance. Following this review process, we set three research questions to contribute key findings.

\subsubsection{Farmers' Knowledge Background}

Many of prior studies show farmers' knowledge and information gaps are responsible for over-fertilization. In the context of Bangladesh, we review papers to acquire farmer groups' knowledge gaps as an influencing factor to massive fertilization. For example, Mohammadi et al. [18] showed his study that the years of experience, the level of education, awareness of organic farming have a significant effect on a number of fertilizers utilized by farmers. There are several reasons for over-application of fertilizers in China: the farmers' traditional notion of 'high fertilizer input, high yield output', easy access to fertilizer markets [19-21]. Lack of knowledge, availability, and lack of getting opportunity towards organic based fertilizers are the key reasons for not using compost fertilizer [22]. According to Waithaka et al. [23] the use of both manure and fertilizer reciprocally influence each other and are strongly influenced by household factors. Illiterate and the low-income group use the mass amount of inorganic fertilizers [28]. Previous studies indicated that the lack of education, and knowledge about organic fertilizers, traditional perception on fertilization, and household status are majorly associated with mass fertilization; even these factor oriented problems exists mainly in the developing countries.

Zhang et al. [24] made a field level research in Northwest China. Results show the economic benefits of overcoming poverty are greatest for the lowest income farmers. The study also found the farmers have the lacking of proper information [29] about rational fertilization. Pan et al. [25] found that high fertilizer use intensity is a serious issue throughout China. The lack of knowledge of Chinese farmers has been found to be the primary constraint. Fan et al. [26] showed his work that excessive $\mathrm{N}$ input may result from a conventional practice of Chinese vegetable growers. They lack the skill of modern agro technology that influences them inefficient fertilization. We viewed poverty, lack of knowledge and information, lack of modern technology affect agricultural sustainability triggering farmers to over amount of fertilizers to their croplands for gaining high yields. The lack of policy and 
guidance supports and fertilizer companies fuel the problems to miserable conditions. In the developing nations, farmer groups are marginalized more than other social classes.

In China, there is a significant association of mass inorganic fertilization with technological inadvancement, lack of scientific knowledge and the shortage of proper information, and smallholder farm size [27]. Zhou et al. [28] showed that gains in crop yield and higher earnings goals are positively correlated with fertilizer use intensity. But, higher education level significantly reduces the probability of over-fertilization. Younger farmers, better-educated, and food secured farmers and net sellers of food grains apply large quantities of organic manure [29]. Educated, affluent, information-rich farmers and farmers of large farm size are very much cautious an about agro ecosystem; they, therefore, use excessive amount of organic manures and less amount of inorganic fertilizers.

It is worth noting that poverty, illiteracy, knowledge and information gap, traditional agriculture, and older age are the root causes of fertilizer intensity. But, whether traditional way of fertilization and farmers' younger age influence over-fertilization that has not yet been studied. These are identified as study gaps to be a significant scope to further research.

\section{RQ1 (research question): How does traditional way of fertilization influences excessive amount of inorganic fertilizers?}

RQ2: What type of impact does farmers' younger age generate on fertilization sustainability or over-fertilization?

Traditional way of fertilization can be defined as an approach of fertilization by which small, unaware, rental land farmers, and farmers' younger age use the high amount of chemical fertilizers to gaining high crop yield and money, without the consideration of agro environmental woes. It is familiar that excessive and indiscriminate use of chemical fertilizers and insecticides are seriously harmful to agro environment across the world.

\subsubsection{Farming Capitals}

Farming capitals mean lands and agriculture related resources (seed, fertilizer, pesticides, cash money, machines, labor, water, and soil). In Bangladesh, landless farmers are more than those of land owners as rental land farming have been gotten popularity since 1960s. Usually, landless and small farmers' rental lands from land elites (generally migrated to cities) for one year at a high price. Farmers intend to gain high yield and income from the land within the short tenure contracted. High gaining frequently depends on high input (fertilizers and insecticides) provision to cropland.

Farmland rental was helpful to reducing the consumption of fertilizers and chemicals in agricultural production [30]. Replacing labor with machine is an important way to use more rational amounts of fertilizers and chemicals than those with low productivity [30]. Nambiro [31] identifies in his study that the growth of a cash crop, off-farm income, and use of improved maize seed positively and significantly influenced adoption of inorganic fertilizer. The lack of knowledge, availability, and lack of getting opportunity towards organic based fertilizers are the key reasons for not using compost fertilizer [22]. The prior studies showed that agricultural machines, off-farm income, improved seeds, lack of composts and growth of cash crop play a driving role to increased fertilization.

$\mathrm{Ju}$ [27] showed in a research work based on China agriculture that there is a significant association of mass inorganic fertilization with technological inadvancement, and smallholder farm size. The low-income group (household factors) uses the mass amounts of inorganic fertilizers [23]. In addition, irrigation, gains in crop yield, and higher earnings goals are positively correlated to fertilizer use intensity [28]. Chianu [29] investigated out that food secure farmers, net sellers of food grains, farmers who have diversified into many crops, they apply high amount of organic manures. These mean crop secured farmers become green farmers when they have fulfilled their primary agricultural needs and they are triggered to use rational and organic fertilizers for the sake of ecology. But poverty and knowledge gaps play a striking role to use over use of chemical fertilizers. Part from, mechanized rental land farming in China is helpful to reducing the consumption of fertilizers and chemicals in agricultural production [30]; on the other hand, small size farmlands are responsible for massive fertilization. Prior researchers did not study the effect of rental land farming in non-mechanized agricultural society yet. Thus, we produce an effort to study the factor (rental land farming) to the use of over-fertilization.

\section{RQ3: Does rental land farming play a significant role in mass fertilizer consumption?}

It is viewed that rental land farmers undoubtedly cultivate their lands using traditional way of fertilization as they have no own land, agricultural training, and mechanization facility (table 1).

\subsubsection{Fertilizer Governance}


"Sustainable fertilizer governance refers to a process by which government agricultural offices play a driving role to access the farmers to rational amounts of fertilizers, to fertilization guidance, to inclusive agro trainings, and to agricultural mechanization so that agro environment can be sustainable." Access to an agricultural extension agent is positively and significantly influenced the adoption of inorganic fertilizers [31]. The small size of fertilizer market in most countries is an important factor in relatively high farm-gate prices and low fertilizer use [32]. Zhou [28] expressed that the distance market of fertilizers are negatively correlated with fertilizer use intensity. That means large and short distant markets of fertilizers are associated with over-fertilization. Bangladesh fertilizer market and its accessibility are very convenient to all sorts of farmers. But agricultural extension agent (fertilizer administration-locally called them agriculture bloc supervisor) are not easy accessed to the small farmers. The farmers can not be able to receive any guidance about sustainable fertilization. However over-amounts of fertilization in Bangladesh are increasing steadily across the country. So we make an effort to examine what are the reasons of the effects.

\subsection{Theoretical Background}

Bangladesh farmers community, to a wider context, are unconscious of agro environment- as most of them are illiterate and untrained-so they cultivate their lands guided by their habits, customs, prolonged practice grasped from nearby senior farmers, high gaining goal within a short period because of their financial vulnerability. We follow two theoretical backgrounds such as 'practice theory' and 'theory of environmental sustainability'. How practice makes a man habitual in his daily life that has been detailed in the practice theory mainly. The practice may be positive or negative which turns into a habit resulting in something for society or ecology. Practice theory we discuss in the study to accommodate the environmental aspects of over-fertilization. Likewise, theory of environmental sustainability has been applied here to scale up the impacts of massive fertilizer use in Bangladesh. In fact, we follow the theories to be guided but make an effort to plus some new ideas to them.

\subsubsection{Practice Theory}

In practice theory, the French sociologist Pierre Bourdieu [33] developed the notion of 'habitus' to capture 'the permanent internalization of the social order in the human body' [34] whilst recognizing 'the agent's practice, his or her capacity for invention and improvisation' [35]. To be a successful living, human being has to struggle constantly through a certain fruitful practices. One can construct a good life when field strategy and habitus come together a good fitting. The habitus-

" ...produces strategies which, even if they are not produced by consciously aiming at explicitly formulated goals...turn out to be objectively adjusted to the situation" [33].

Habit is required; but everybody has to adopt suitable decision according to the goals set previously. Because planning is a matter of rationality and thus management has to be carried out according to suitable demands derived from situation. Apart from, time and information have to be fruitful and effective when they appeared as they are not unlimited. But it is a reality that practice can make a plan and strategy effective and complete - it creates experiences - that leads anybody to success. A closely related notion to Bourdieu's habitus is Michel Fouchault's [36] concept of 'discipline'. Like habitus, discipline is a structure and power that has been impressed on the body forming permanent dispositions [34].

Discipline is, in fact, a supplement notion to practice that can make a man succeeded. One's practice may be unplanned, undisciplined, and demoralized that cannot produce good outcomes as they work in a totality manner observed among the natural apparatus. Schatzki [37] said, 'the society is a field of embodiment, materially interwoven practices centrally organized around shared practical understandings'. Basically it is true that skill, understanding the situation, and work accordingly can accelerate success when practice gets interlinked with. Without hard work and understanding job nature, practice may go in vain.

The study follows 'practice theory' to be guided scientifically and to make a quality study report on the basis of adding new notion to the theory. However, we intend to extend Schatzki's notion (skill and understanding are required to success with practice) within practice theory. Fertilization sustainability would be succeeded at that situation when farmers will apply their skill (manual or mechanized) with better understanding to agriculture achieved by practices for a long time. We, therefore, extend a notion outcome of mechanized skill and understanding (consciousness) of farmers that can accelerate fertilization sustainability not only in Bangladesh but also in LDCs and developing countries.

\subsubsection{Theory of Environmental Sustainability}


According to, the neoclassical growth model it worked until the company had agricultural structures or preindustrial [38], with population density and low productions and disseminated; the prevailing culture, especially in agricultural areas, was to reuse and recycling of material resources. This was a self-purification process to a substantial balance between economy and ecology. With the growth of population, urbanization, production and consumption increase alongside; the increased use of natural resources and production of waste started to rupture of natural equilibrium. The optimistic view of the economy growing that characterized most of the 20th century began to enter a crisis in the ' $60 \mathrm{~s}$, when, with the first phenomenon of smog, scarcity and pollution[39]. The last century flourished the western developed countries through a rapid growth in manufacturing sectors resulting in emission and discharge of huge amounts of toxic wastes to natural environments; though presently they are very conscious about environmental sustainability and toxic wastes in the countries are being disposed and emitted at a global safe standard. But emerging developing countries entered into the list countries of toxic industrial wastes (China, India, Brazil, Turkey, Nigeria, Vietnam, Bangladesh, and Pakistan).

The excessive trust towards perfectly substitutable resources through market mechanisms and technological progress, led to the general assumption neoclassical to clash with the finite reality of the natural environment [40]. From this point of view, the traditional economy intended to produce and exchange goods and services using scarce resources to be allocated more efficiently among alternative uses to satisfy human needs [41]. Market mechanisms and technological progress trust of adequate substitutes of natural resources. Though it is partly authenticate; to the wider context it is a suicidal confidence as environmental woes have already been a serious headache of global governance. Global consumerist culture expedites economic growth across the globe resulting in a drastic decay of natural resources and thus the wastes create the environment worst.

In fact, theory of environmental sustainability produced following the industrial wastes to unsustainable environment. But presently a lot of other economic and business sectors contribute toxicity by chemical wastes or over- chemicalization of production chain. For example, excessive use of chemical fertilizers and pesticides in the developing countries are affecting the ecological services heavily. We make an effort to extend some new notions to the theory of environmental sustainability based on the agricultural chemical inputs (fertilizers) consumption and their agro ecological consequences. The study aims to find out the socio-economic factors affecting overfertilization causing a great damage to agro environment and it would be a scientific notional extension of the theory.

\section{Methods and Materials}

\subsection{Data Collection}

To collect data on fertilization sustainability we opted anonymous, semi-structured personal interviews with farmers. The method we approached is superior to others (face-to-face, focus group discussion, and phone interviews) in data collection process as semi-structured interview [42] gives farmers an opportunity to explain, increases response rate of finished questionnaires [42].

The questionnaire consists of 18 questions categorized into four parts: (i) personal data of farmers (e.g., sex, age, education, income, family members, and family bearing capability); (ii) farmers' knowledge level about fertilization sustainability (e.g., understanding of fertilization sustainability, way of fertilization, training, amount of fertilizer application); (iii) farmers' capitals (land ownership, land rental status, amount of fertilization in rental lands, availability of fertilizers); (iv) fertilizer governance (e.g., role of agriculture extension agents, soil testing status). We inserted a copy of interview questions at the end of the study report as Supplementary Materials.

The questionnaire has been prepared in non-scientific language [42] for clarification of the questions to the farmers. The set of questions was developed upon consultations with a good numbers of researchers and experts so that it can hold scientific ethics and can be appeared easier to farmers. A pilot study was conducted with eight farmers before full study to prove its quality.

\subsubsection{Sites of the Study}

Four districts out of sixty four in Bangladesh were selected for the study. The districts chosen are important for agriculture; they are diversified in terms of agricultural pattern, farmers' characteristics, and fertilization nature. For the diversification of these agricultural areas the credibility and reliability of the data can be considered higher; as there are an established relationship between researchers and farmers [42]. We conducted 210 interviews with farmers in 2016 and opportunist sampling [42] was chosen. The eight districts include: Manikgonj (N=90), Dinajpur $(\mathrm{N}=40)$, Moulvibazar $(\mathrm{N}=40)$, and Noakhali $(\mathrm{N}=40)$. 

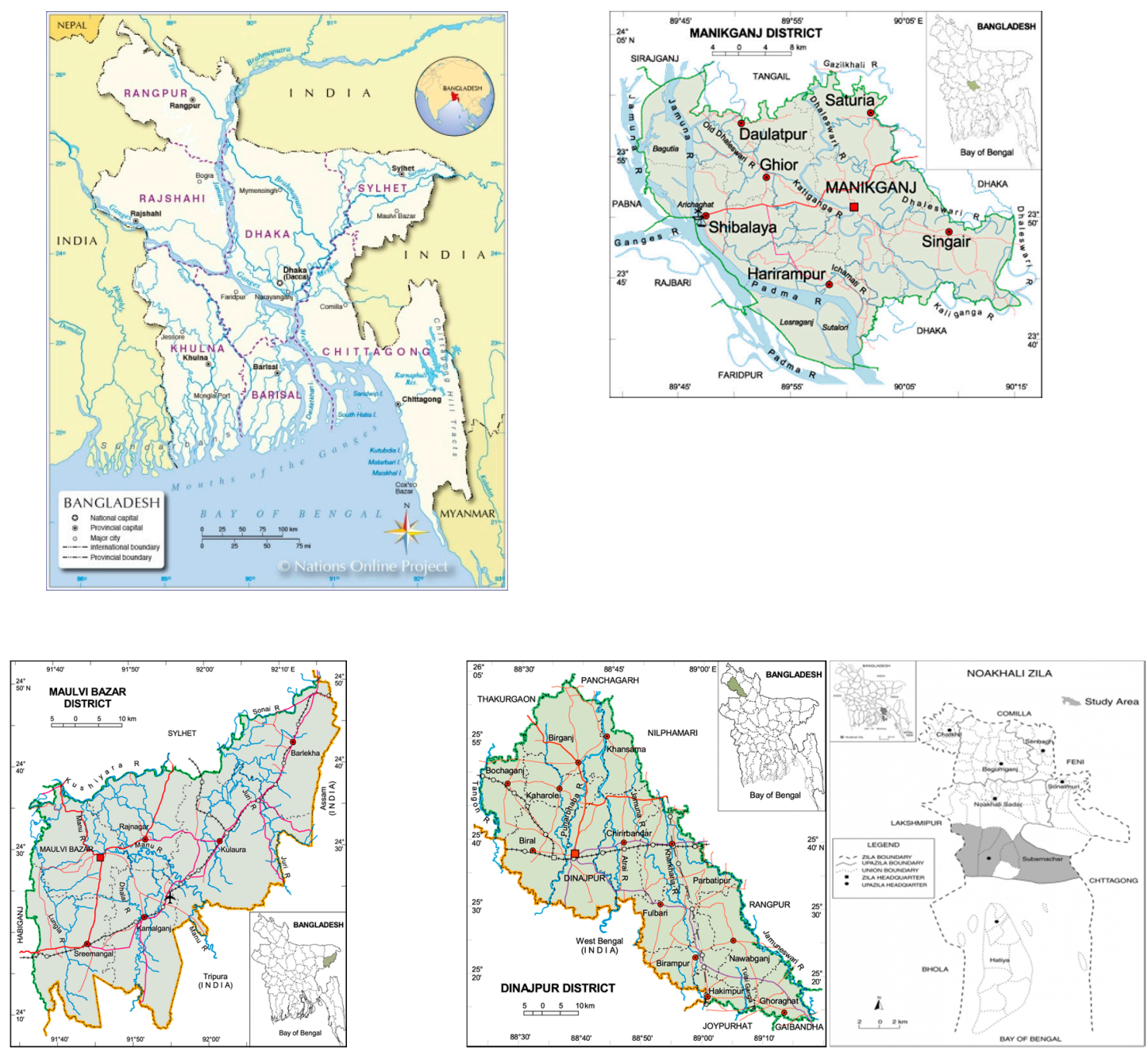

Figure1: The areas of study-Bangladesh (in South Asia); Manikgonj (common agriculture), Moulvibazar (hilly), Dinajpur (growth center), Noakhali (salinity prone).

\subsubsection{Data Process and Analysis}

Data collected from interviews has been inputted directly into SPSS (SPSS Inc. Released 2007. SPSS for Windows, Version 16.0. Chicago, SPSS Inc.) for statistical analysis. Descriptive statistics has been divided into two parts: (i) line graph for showing fertilizer consumption in comparison between world average and Bangladesh; (ii) tabular statistics shows the basic socio-economic and demographic features of farmers using descriptive tools: percentile, standard deviation and variance. To obtain the effects among the variables we apply General Linear Model (GLM). Applying Univariate Analysis of Variance of GLM we find out Type III Sum of Square, DF, F, and $\mathrm{P}$ value for examining the effects and interaction between dependent and independent variables. We use two dependent variables such as excessive amount of fertilization and small amount of fertilization. The dependent variable small amount of fertilization has been used as a cross-analysis tool for confirming the significance level.

\section{Results}

\subsection{Descriptive Statistics}

We describe the current information of global average and Bangladesh using line graph (figure2). Figure 2 shows comparative data of fertilizer consumption ranging time span from 2002 to 2015. Bangladesh consumes this agro input an amount higher than that of global average. Its consumption accounted for 188 tons in 2002 that increased to 275 in 2012. On the other hand, global average usage was 103 and 135 tons, respectively in 2002 and 2012. Likewise, China, India and most of other developing countries consume higher amounts of chemical fertilizers than global average. 


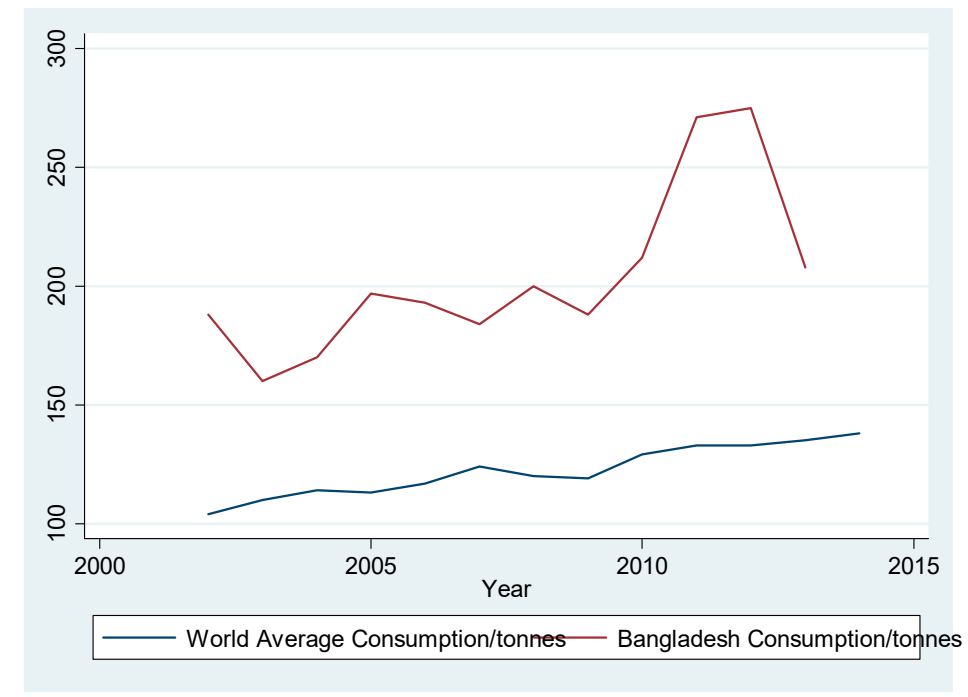

Figure2: Fertilizer Consumption: World Average and Bangladesh 2000-2015

In global terms, china has contributed about $33 \%$ of $\mathrm{N}$ and $36 \%$ of $\mathrm{P}$ in nutrient surplus [43]. Table 1 presents the basic and common socio-economic and demographic features of Bangladesh farmers. It is worth noting that $59.6 \%$ of the respondents are more than 41 years old, $84.8 \%$ are the farmers of less than BDT $6,000.00$ monthly income and $47.4 \%$ are illiterate. Among the respondents, $61.0 \%$ have no their own lands and $60 \%$ are using excessive amount of chemical fertilizers. $42.4 \%$ of the respondents run their farming activities in rental lands and $62.9 \%$ follow traditional way of fertilization. $65.7 \%$ and $74.3 \%$ are untrained and unconscious of agro environment respectively. 
Table1: Descriptive Statistics $(N=210)$

\begin{tabular}{|c|c|c|c|c|}
\hline Variables & Attributes & Percentage & SD & $\mathbf{V}$ \\
\hline \multirow[t]{2}{*}{ Age } & $<40$ years & 40.4 & 0.49 & 0.24 \\
\hline & $>41$ years & 59.6 & & \\
\hline \multirow[t]{2}{*}{ Income } & $<$ BDT 6000.00 & 84.8 & 0.73 & 0.54 \\
\hline & > BDT 6000.00 & 15.2 & & \\
\hline Education & $\begin{array}{l}\text { Illiterate } \\
\text { Literate( up to } 12 \\
\text { grades) }\end{array}$ & $\begin{array}{l}47.4 \\
52.6\end{array}$ & 0.5 & 0.25 \\
\hline \multirow[t]{2}{*}{ Amount of Fertilization } & $\begin{array}{l}\text { Excessive amount } \\
\text { (YES) }\end{array}$ & 63.3 & 0.48 & 0.24 \\
\hline & Small amount (NO) & 36.7 & & \\
\hline \multirow[t]{2}{*}{ Agro training Adoption } & YES & 34.3 & 0.48 & 0.23 \\
\hline & NO & 65.7 & & \\
\hline \multirow[t]{2}{*}{$\begin{array}{l}\text { Traditional Way of } \\
\text { Fertilization }\end{array}$} & YES & 62.9 & 0.72 & 0.60 \\
\hline & NO & 19.5 & & \\
\hline \multirow[t]{2}{*}{ Land Ownership } & Landless (YES) & 61.0 & 0.49 & 0.24 \\
\hline & $\begin{array}{l}\text { Non-rental land } \\
\text { owners (NO) }\end{array}$ & 39.0 & & \\
\hline \multirow[t]{2}{*}{ Environmental Consciousness } & YES & 25.7 & 0.44 & 0.19 \\
\hline & NO & 74.3 & & \\
\hline \multirow[t]{2}{*}{ Rental Land Farming } & YES & 32.4 & 0.47 & 0.22 \\
\hline & NO & 67.6 & & \\
\hline \multicolumn{5}{|l|}{ Cooperation of Fertilizer } \\
\hline Administration & YES & 36.2 & 0.67 & 0.45 \\
\hline & NO & 63.8 & & \\
\hline
\end{tabular}

Note: Basic socio-economic and demographic information of responding farmers

Table 2 displays the effects of the farmers' technological and economic variables on over- fertilization. It means how traditional way of fertilization and rental land farming affects fertilization sustainability. The effects have been shown using General Linear Model (GLM-corrected). The results show that the effects of traditional way of fertilization on excessive amount of fertilization are strongly significant at $1 \%$ level. The impact of rental land farming on over-fertilization is not significant individually. But, it is viewed that there is a strong and significant interaction between traditional way of fertilization and rental land farming at 5\% level. Statistically, it is argumentative that rental land farming has a significant effect on massive fertilization. 
Table2: General Linear Model: Univariate Analysis Tests of Between-subjects Effects

Dependent Variable: Excessive Amount of fertilizer

\begin{tabular}{cllll}
\hline Source & Type III Sum of Squares & df & F & Sig. \\
\hline Corrected Model & $3.394^{\mathrm{a}}$ & 3 & 5.116 & $.002^{* * *}$ \\
Intercept & 28.582 & 1 & 129.259 & $.000^{* * *}$ \\
Traditional Way of Fertilization (FW_) & 3.127 & 1 & 14.142 & $.000^{* * *}$ \\
Rental Land Farming (LN_) & 0.161 & 1 & 0.729 & 0.394 \\
FW_*LN_ & 0.998 & 1 & 4.514 & $.035^{* *}$ \\
Error & 45.772 & 207 & & \\
Total & 78 & 211 & & \\
Corrected total & 49.166 & 210 & &
\end{tabular}

a. $\mathrm{R}$ Squared $=.069$ (Adjusted R Squared $=.056)$

$$
\text { Note: }{ }^{* *} \mathrm{p}<.05 ;{ }^{* * *} \mathrm{p}<.01
$$

The significance interaction between traditional way of fertilization and rental land farming has been presented in figure 2. The two lines have been interacted each other. If they do not get interactive, they would not have crossed each other.

\section{Estimated Marginal Means of Excessive amounts of fertilization}

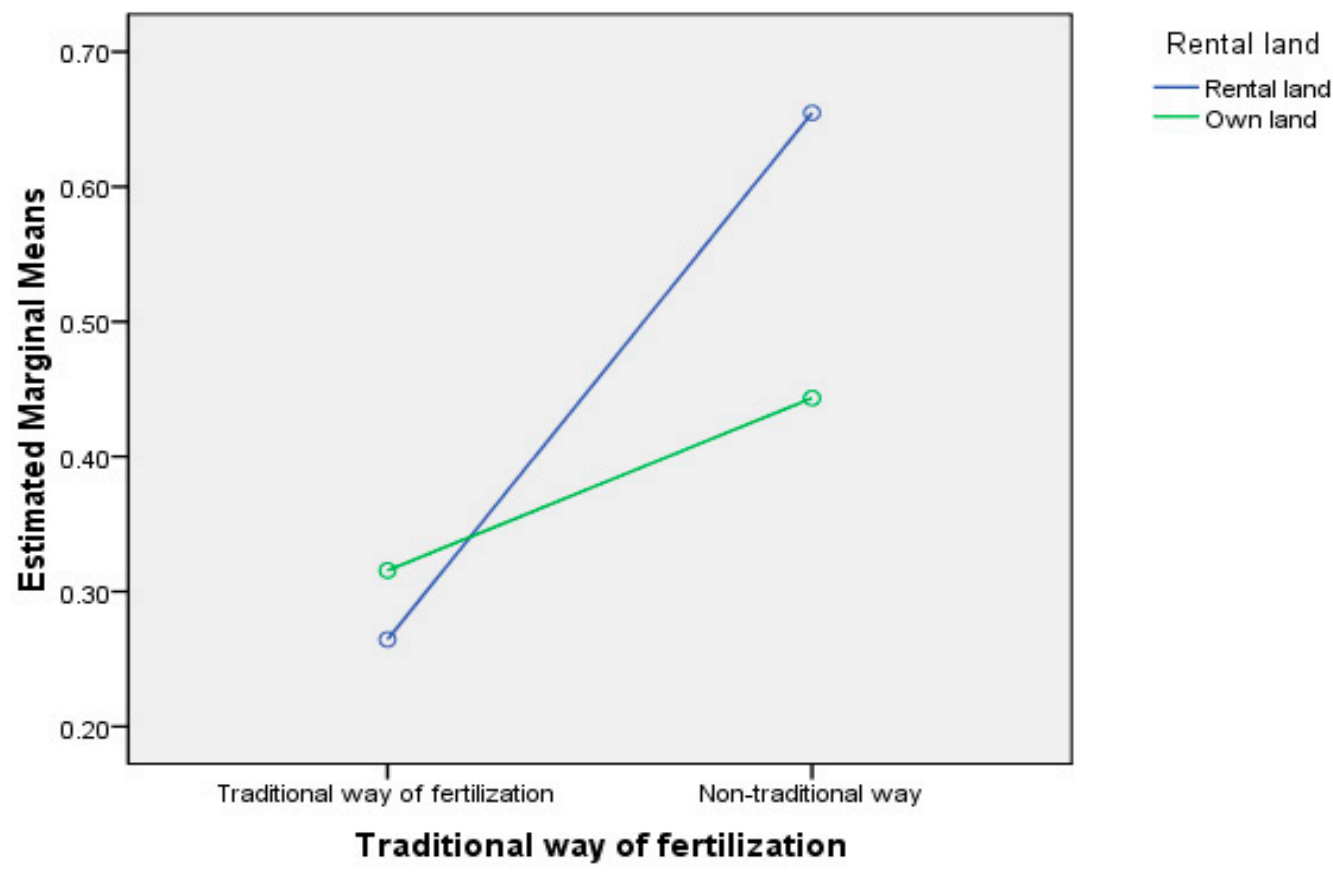

Figure3: Interaction of traditional way of fertilization and rental land farming towards the excessive amount of fertilization

Table 3 is also a corrected General Linear Model showing the impact of socio-demographic variables on mass fertilization. The results show the significant effects of farmers' younger age and their illiteracy on excessive amount of fertilization. Their effective interaction is significant at $5 \%$ level. The results offer the value of $\mathrm{R}$ Square .028 . 
Table3: General Linear Model: Univariate Analysis Tests of Between-subjects Effects

Dependent Variable: Excessive Amount of Fertilization

\begin{tabular}{cllll}
\hline Source & Type III Sum of Squares & df & F & Sig. \\
\hline Corrected Model & $1.393^{\mathrm{a}}$ & 3 & 2.012 & $.113^{* *}$ \\
Intercept & 24.377 & 1 & 105.626 & $.000^{* * *}$ \\
Younger Farmers- below 40 Years (AG_) & .708 & 1 & 3.067 & $.081^{*}$ \\
Farmers Illiterate (ED_) & .887 & 1 & 3.844 & $.05^{* *}$ \\
(AG_ED_) & .033 & 1 & .144 & .705 \\
Error & 47.773 & 207 & & \\
Total & 78.000 & 211 & & \\
Corrected total & 49.166 & 210 & &
\end{tabular}

R Squared $=.028$ (Adjusted R Squared $=.014$ )

$$
\text { Note: }{ }^{*} \mathrm{p}<.10 ;{ }^{* *} \mathrm{p}<.05 ;{ }^{* * *} \mathrm{p}<.01
$$

There has been presented a cross analysis in table 4 as per the confirmation between dependent and independent variables stated in the tables above. We estimate here the effects of non-traditional way of fertilization, Non-rental land farming, farmers' older age, and literacy on small amount of fertilization. The results show that all variables have significant effect on small amount of fertilization at 5\% and $10 \%$ level. These prove that traditional way of fertilization; rental land farming, younger age, and illiteracy have a significance effect on excessive amount of fertilization.

Table4: General Linear Model: Univariate Analysis Tests of Between-subjects Effects

Dependent Variable: Small Amount of Fertilization

\begin{tabular}{ccccc}
\hline Source & Type III Sum of Squares & df & F & Sig. \\
\hline Corrected Model & $3.682 \mathrm{a}$ & 5 & 3.339 & $.006^{* *}$ \\
Intercept & 11.763 & 1 & 53.328 & $.000^{* * *}$ \\
Non-traditional Way of Fertilization (F_W) & 1.929 & 1 & 8.746 & $.003^{* *}$ \\
Non-rental Land Farming (L_N) & 0.371 & 1 & 1.684 & 0.196 \\
F_W*L_N & 0.697 & 1 & 3.159 & $.077^{*}$ \\
Farmers Literate (E_D) & 0.776 & 1 & 3.518 & $.062^{*}$ \\
Older Farmers & 0.644 & 1 & 2.918 & $.089^{*}$ \\
Error & 45.218 & 205 & & \\
Total & 613 & 211 & & \\
Corrected total & 48.9 & 210 & & \\
\hline
\end{tabular}

a. R Squared $=.075$ (Adjusted R Squared $=.053$

$$
\text { Note: }{ }^{*} \mathrm{p}<.10{ }^{* *} \mathrm{p}<.05 ;{ }^{* * *} \mathrm{p}<.01
$$

Summary: excessive amount of fertilization is significantly interacted and correlated with-

- Traditional way of fertilization ( $\mathrm{p}$ value $=000)$

- Rental land farming ( $\mathrm{p}$ value=.035)

- Farmers' younger age ( $\mathrm{p}$ value=.081)

- Farmers' illiteracy ( $\mathrm{p}$ value $=.05)$

\subsection{Discussion and Conclusions}


We discuss the results of effects and interaction between variables stated in summary that are statistically significant in details on the basis of logic, arguments, references, and objectivity. The results show that the effects of traditional way of fertilization, rental land farming, and younger aged farmers on over-fertilization are statistically significant. Traditional way of fertilization has a strong significance as it is significant at 1 percent level. But others are at 5 and 10 percent level. We discuss here to estimate which ones are key findings and which are consistent with previous studies.

First, traditional way of fertilization: $62.9 \%$ of the respondents in Bangladesh cultivate their lands following traditional fertilization way. The result presents that traditional way of fertilization is statistically significant at 1 percent level. Still in 21th century, Bangladesh agriculture (fertilization) is technologically non-advanced including other sectors just as other developing countries. Traditional way means an approach which is based on nonmechanized manual fertilization. This approach has been established following closed senior farmers' fertilization and such agro customs (habits, practice) existing in the society for a long time as they have no training and technological efficiency. The way has been established bearing a notion 'more fertilizer, more yields'. The farmers are using huge amount of fertilizers to gain high yields from their rental lands within a short contracted tenure. The gains in China agricultural productivity obtained through agricultural reform initiated in late 1970s [19]. The reform was actually based on mechanization and modernization of China agriculture. But before 1978 China agriculture was based on a rapid increase in the consumption of fertilizers and chemicals [8,30]. On that time, China agriculture was being cultivated in traditional fertilization way; but this field has yet been studied. In addition, Fan et al. [26] showed in of his studies that excessive $\mathrm{N}$ input may result from conventional practice of Chinese vegetable growers. Traditional way of fertilization, therefore, is a key finding that belongs to an extension of conventional agricultural practice model.

Second, rental land farming: the result displays that $63.3 \%$ of the respondents consume excessive amount of fertilizers. It is also worth noting that $42.4 \%$ of the respondents cultivate their lands on rental basis. The effects of rental land farming on over-fertilization are statistically significant at $5 \%$ level (on the basis of interaction with traditional way of fertilization). As most of the farmers (61.0\%) have no own lands, they have to run their cultivation renting-up the crop lands from others (elite farmers mostly migrated to townships) by an informal contract for mainly one year term. The land rental price is very high due to high competition among small or landless farmers; so they has a best effort to gain high yields within this short tenure using high inputs (fertilizers). It is worthily mentionable that inorganic fertilizers have an easy access rather than organic manures in Bangladesh. Bangladesh farmers would like to produce agro-products at a high amount from their leased- up land at any cost [16]. Therefore, they use excessive amount of fertilizers and insecticides to grow more foods within a short time from a small area of lands [16].

Liu et al. [30] presented the rapid growth of rental land markets in China and the association of farmland and agricultural productivity. He also suggested that replacing labor with machines is an important way to use rational amount of fertilizers. But it proves that China agriculture was highly dependent on massive amount of fertilizers before mechanization. Bangladesh agriculture (especially fertilization) is highly labor intensive, not mechanized. That's why, the effects of rental land farming on massive fertilization is significant not only in Bangladesh but also in other developing countries. For other example, more than half of the increased crop production in China was based on a rapid increase in the consumption of fertilizers and chemicals [4, 8]. It is noted that fertilizer based croplands were rental basis for a long time.

Third, farmers' younger age: Around 40\% farmers of the respondents are younger aged (below 40 years). The statistical results offer that younger farmers apply the excessive amount of inorganic fertilizer than older farmers. Majority of farmers in Bangladesh hold the family financial responsibility leaving school because of their senior family members are unable to earn livelihood due to inevitable reasons. On the other hands, they have no own lands and other income source; so they use over amount of fertilizers in their rental or own small lands for higher gaining. Even, they have no training and environmental consciousness that causes environmental losses sharply. As a result, younger farmers have a strong impact on over-fertilization. Younger farmers, better-educated, food secure farmers, and net sellers of food grains apply large quantities of organic manure [29]. But in Bangladesh it is proven that younger farmers use more amounts of inorganic fertilizers as they have hardly education and affluence (table 1).

Fourth, farmers' illiteracy: farmers' illiteracy is significantly interacted with excessive amount of fertilization and it is consistent with the studies of Mohamadi et al. and Waithaka et al. For example, the years of experience, the level of education, awareness of organic farming have a significant effect on a number of fertilizers utilized by farmers [18]. Illiterate and the low-income group use the mass amount of inorganic fertilizers [23]. That's why it is significant and consistent with these studies. for-

The study contributes 3 key findings as follows (figure4): the excessive amount of fertilization is being caused 
1. Traditional way of fertilization

2. Rental land farming

3. Farmers' younger age

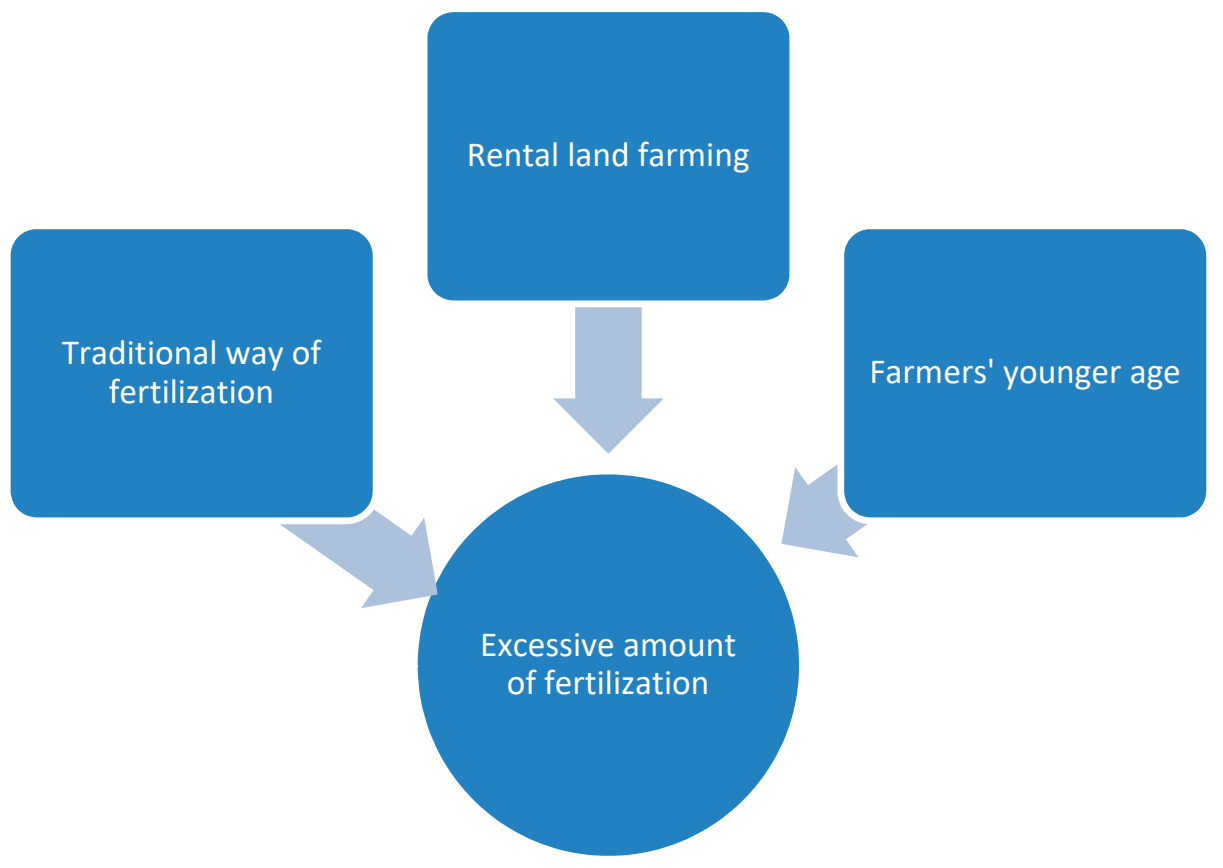

Figure4: Converging Radial shows the relationship or effectiveness of excessive amount of fertilization with traditional way of fertilization, rental land farming, and farmers' younger age

The 3 key findings support practice theory and theory of environmental sustainability. Traditional way of fertilization and rental land farming has been an agricultural custom, habit or practice in Bangladesh for a long time. But the custom and practice lack knowledge, technology, planning, and consciousness. As a result, though these indicators contribute agricultural production growth (unsustainable), they cause environmental degradation highly. The findings of the study are new extension of the 2 theories as they have not yet been applied in agricultural (fertilization) sectors in previous studies. During data collection there was a trouble regarding understanding of interview questions. The illiterate farmers could not understand the interview questions and thus they were almost incapable to answer accurately and completely. Lastly, we collected data using unscientific language. The study has been used the data collected from one country (Bangladesh) and it has been regarded another limitation. The data might not be a complete representation of other developing countries. It is also worth noting that it was very hard to visit different countries to collect first-hand data for inevitable reasons.

We have several recommendations for further research on fertilization sustainability:

1. How to mechanize the agricultural system increasing large hold farms specially in developing countries?

2. How to introduce in-field guidance models persistently in technologically non-advanced agricultural societies?

Finally it is found that Bangladesh including other developing countries get induced with over-fertilization causing environmental woes. The results show that traditional way of fertilization, rental land farming, and farmers' younger age has a significant effect on excessive amount of fertilization. On other word, technologically nonadvanced societies face the problem heavily regarding fertilization sustainability. State authorities can come forward with finance, technology, literacy, and in-field guidance for farmers to cope these obstacles. Policy makers can be able to formulate national fertilizer policy following the findings of the study.

Acknowledgements: The authors would like to be thankful to the interviewee farmers in rural for their cooperation in data collection activities. Moreover, we are grateful to Shanghai University Library for Digital Database. We owe to a PhD candidate of Beijing Normal University named Md Bayezid Alam for his technical assistance in writing the paper.

Author Contributions: Dunfu Zhang designed and analyzed data of the research work; K. M. Atikur Rahman collected data and wrote the paper. 
Conflicts of Interest: The authors declare no conflict of interest. 


\section{References}

1. Godfray, H.C.J.; Beddington, J.R.; Crute, I. R.; Haddad, L.; Lawrence, D.; Muir, J.F.; Pretty, J.; Robinson, S.; Thomas, S.M.; Toulmin, C. Food security: The challenge of feeding 9 billion people. Science 2010, 327, 812-818, DOI. $10.1126 /$ science. 1185383 .

2. FAO. FAOSTAT database: agriculture production. Food and Agriculture Organization of the United Nations: Rome, Italy, 2015.

3. Tilman, D. The ecological consequences in changes in biodiversity: a search for general principles. Ecology 1999, 80, 1455-1474.

4. Tilman, D.; Cassman, K.G.; Matson, P.A.; Naylor, R.; Polasky, S. Agricultural sustainability and intensive production practices. Nature 2002, 418, 671-677, DOI: 10.1038/nature01014.

5. Zhang, F.S.; Chen, X.P.; Vitousek, P. Chinese agriculture: An experiment for the world. Nature 2013, 497, 33-35, DOI: 10.1038/497033a.

6. Chen, X.P.; Cui, Z.L.; Fan, M.S.; Vitousek, P.; Zhao, M.; Ma, W.Q.; Wang, Z.L.; Zhang, W.J.; Yan, X.Y.; Yang, J.C.; et al. Producing more grain with lower environmental costs. Nature 2014, 514, 486-489, DOI: 10.1038/nature13609.

7. Tilman, D.; Reich, P. B.; Knops, J.; Wedin, D.; Mielke, T.; Lehman, C. Diversity and productivity in a long-term grassland experiment. Science 2001, 294, 843, DOI: 10.1126/science.1060391.

8. Jiao, X.Q.; Lyu, Y.; Wu, X.B.; Li, H.G.; Cheng, L.Y.; Zhang, C.C.; Yuan, L.X.; Jiang, R.F.; Jiang, B.W.; Rengel, Z.; et al. Grain production versus resource and environmental costs: Towards increasing sustainability of nutrient use in China. J. Exp. Bot. 2016, 67, 4935-4949, https://DOI.org/10.1093/jxb/erw282.

9. Intergovernmental Panel on Climate Change 2006. N2O emissions from managed soils and CO2 emissions from lime and urea application. Chapter 11. Intergovernmental Panel on Climate Change guidelines for national greenhouse gas inventories. Volume 4: Agriculture, forestry and other land use. Available online: http://www.ipccnggip.iges.or.jp/public/2006gl/pdf/4 Volume4/V4 11 Ch11 N2O\&CO2.pdf. (accessed on 15 July 2017.

10. FAO. World Fertilizer Trends and Outlook 2018. FAOSTAT: Rome, Italy, 2015, pp. 18.

11. Serpil, S. Investigation of effect of chemical fertilizers on environment. APCBEE Procedia. 2012, 1, 287 - 292, https:// DOI: 10.1016/j.apcbee.2012.03.047.

12. Bangladesh Agricultural Research Council (BARC). Fertilizer Recommendation Guide- 2005; Soil Publications: Gazipur, Bangladesh, 2005.

13. U.S. Environmental Protection Agency. Hypoxia in the northern Gulf of Mexico: an update by the EPA science advisory board, EPA-SAB-08-00. U.S Environmental Protection Agency: Washington D.C., USA, 2007.

14. East Pakistan Bureau of Statistics (EPBS). Statistical Abstract for East Pakistan (1950-51 to 1959-60). Govt. of East Pakistan, Bureau of Statistics: Dhaka, Pakistan, 1964.

15. Quasem, M. A. Fertilizer use in Bangladesh: 1965-66 to 1975-76; Bangladesh Institute of Development Studies: Dhaka, Bangladesh, 1978.

16. Rahman, K. M. A. Agrochemical use, environmental and health hazards in Bangladesh. Int. Res. J. Inter. Multi. Stud. 2015, 1, 75-79. Available online: http://www.irjims.com/files/K_5xhsw1pt.M-Atiqur-Rahaman.pdf. 22.

17. Bruce, K. The great lakes. An environmental atlas and resource book. US EPA \& Environment Canada; 1 st ed.; Chicago, USA, 1988; ISBN-13: 978-0662234418.

18. Mohammadi, H.;Mohammadi, A. M.; Nojavan, S. Factors affecting farmer's chemical fertilizers consumption and water pollution in Northeastern Iran. J. Agricult. Sci. 2017, 9, 234-241, http://dx.doi.org/10.5539/jas.v9n2p234.

19. Zhang, F.S.; Cui, Z.L.; Fan, M.S.; Zhang, W.F.; Chen, W.P.; Jiang, R.F. Integrated soil-crop system management: Reducing environmental risk while increasing crop productivity and improving nutrient use efficiency in China. $J$. Environ. Qual. 2010, 40, 1051-1057, DOI:10.2134/jeq2010.0292.

20. Gao, L.L.; Huang, J.K.; Rozelle, S. Rental markets for cultivated land and agricultural investments in China. Agric. Econ. 2012, 43, 391-403, DOI: 10.1111/j.1574-0862.2012.00591.x.

21. Kong, K. Y.; Tang, H.M.; Pan, K.; Huang, Z.; Lee, T.H.; Hinnebusch, A.G.; Jin, D.Y.; Wong, C.M. Co transcriptional recruitment of yeast TRAMP complex to intrinsic sequences promotes optimal pre-mRNA splicing. Nucleic Acids Res. 2014, 42, 643-60, DOI: 10.1093/nar/gkt888

22. Karim, R.; Aktar, M. A. Fertilizer use pattern on agriculture in Salua area of Chougachha Upazila, Jessore, Bangladesh. J. Biosci. Agric. Res. 2016, 03, 96-103.

23. Waithaka, M.M.; Thornton, P.K.; Shepherd, K.D.; Ndiwa, N. N. Factors affecting the use of fertilizers and manure by smallholders: The case of Vihiga, western Kenya. Nutr. Cycl. Agroecosyst. 2007, 78, 211-224, DOI: https://dx.doi.org/10.1007/s10705-006-9087-X.

24. Zhang, S.; Gao, P. T.; Norse, Y. D.; Lu, Y.;Powlson, D. Overcoming nitrogen fertilizer over-use through technical and advisory approaches: A case study from Shaanxi Province, northwest China agriculture. Ecosyst. Environ. 2015, 209, 89-99, http://dx.doi.org/10.1016/j.agee.2015.03.002.

25. Pan, D.; Kong, F.; Zhang, N.; Ying, R. Knowledge training and the change of fertilizer use intensity: Evidence from wheat farmers in China. J. Environ. Manag. 2017, 197, 130-139, DOI: 10.1016/j.jenvman.2017.03.069. 
26. Fan, Z.; Lin, S.; Zhang, X.; Jiang Z.; Yang, K. Conventional flooding irrigation causes an overuse of nitrogen fertilizer and low nitrogen use efficiency in intensively used solar greenhouse vegetable production. Agricult. Water Manag. 2014, 144, 1-19, http://dx.doi.org/10.1016/j.agwat.2014.05.010.

27. Ju X.; Gu B.; Wu Y.; Galloway J.N. Reducing China's fertilizer use by increasing farm size. Glob. Environ. Chang. 2016, 41, 26-32, http:/dx.doi.org/10.1016/j.gloenvcha.2016.08.005.

28. Zhou, Y.; Yang, H.; Mosler, H. J.; Abbaspour, K. C. Factors affecting farmers' decisions on fertilizer use: A case study for the Chaobai watershed in Northern China. J. Sustain. Dev. 2010, 4, 80-102, https://doi.org/10.7916/D8C24W3R.

29. Chianu, J. N.; Tsujii, H. Determinants of farmers' decision to adopt or not adopt inorganic fertilizer in the savannas of northern Nigeria. Nutr. Cycl. Agroecosyst. 2004, 70, 293-301, https://doi.org/10.1007/s10705-005-0715-7.

30. Liu, Y.; Wang, C.; Tang, Z.; Nan, Z. Farmland Rental and Productivity of Wheat and Maize: An Empirical Study in Gansu, China. Sustainability 2017, 9, 1678, DOI:10.3390/su9101678.

31. Nambiro, E.; Okoth, P. What factors influence the adoption of inorganic fertilizer by maize farmers? A case of Kakamega District, Western Kenya. Scienti. Res. Ess. 2013, 85, 205-210, https://doi: 10.5897/SRE10.1063.

32. Vlek, P.L.G. The role of fertilizers in sustaining agriculture in sub-Saharan Africa. Fertilizer Res. 1990, 26, 327, https://doi:10.1007/BF01048771.

33. Bourdieu, P. Outline of a Theory of Practice, Cambridge University Press: Cambridge, UK, 1977; ISBN10: 052129164X.

34. Eriksen, T.H.; Nielsen, F.S. A history of anthropology, Pluto Press: London, UK, 2001; pp. 138-161; ISBN 97818496 49186.

35. Bourdieu, P. In other words, Polity: Cambridge, UK, 1990; p. 61.

36. Foucault, M. Discipline and punish: the birth of the prison, Vintage Books: New York, USA, 1979; ISBN 03947276739780394727677.

37. Schatzki, T. Introduction: practice theory, In: Schatzki, T., K. Knorr Cetina and E. von Savigny, 1st ed.; 2001, The Practice Turn in Contemporary Theory, Eds.; Routledge: London, UK, 2001; pp. 50-63, ISBN 0-203-97745-9.

38. Ravera O. La questione ambientale alle porte del terzo millennio, Gregoriana libreria editrice: Padova, Italy, 1998; pp. 184; ISBN 9788877061539. (in Italiano).

39. Carson, R. Silent spring, Houghton Lifflin: New York, USA, 1962; ISBN 10:0618249060.

40. Daly, H.; Cobb, J. Redirecting the economy toward community, the environment, and a sustainable future, Beacon Press: Boston, USA, 1989; pp. 346-347; ISBN 0-8070-4702-3.

41. Turne, R.K.; Pearce, D.W.; Bateman, I. Economia ambientale, Il Mulino: Bologna, Italy, 2003; EAN 9788815095237 (in Italiano).

42. Latawiec, A.E.; Królczyk, J. B;, Kuboń, M.; Szwedziak, K.; Drosik, A.; Polańczyk, E.; Grotkiewicz, K.; Strassburg, B. B. N. Willingness to Adopt Biochar in Agriculture: The Producer's Perspective. Sustainability 2017, 9, 654, DOI. $10.3390 /$ su9040655.

43. West, P.C.; Gerber, J.S.; Engstrom, P. M.; Mueller, N.D; Brauman, K.A.; Carlson, K.M.; Cassidy, E.S.; Johnston, M,.; MacDonald, G.K.; Ray, D.K.; Siebert, S. Leverage points for improving global food security and the environment. Science 2014; 345, 325-328, DOI. 10.1126. 